\title{
Steady State Simulation of 33 kV Power Grid
}

\author{
Kiu Han Teck, Nader Barsoum \\ Electrical and Electronics Engineering, University Malaysia Sabah, Kota Kinabalu, Malaysia \\ Email: nader@ums.edu.my
}

How to cite this paper: Teck, K.H. and Barsoum, N. (2018) Steady State Simulation of $33 \mathrm{kV}$ Power Grid. Journal of Power and Energy Engineering, 6, 106-124. https://doi.org/10.4236/jpee.2018.66007

Received: May 31, 2018

Accepted: June 26, 2018

Published: June 29, 2018

Copyright $\odot 2018$ by authors and Scientific Research Publishing Inc. This work is licensed under the Creative Commons Attribution International License (CC BY 4.0).

http://creativecommons.org/licenses/by/4.0/

\begin{abstract}
An example is presented in this paper relating to power problems in Sandakan power network. Sandakan is a suburb in east coast of Sabah state of Malaysia. The problems were reported with power flow and N-1 contingency in terms of blackout after main grid supply outages with overload and high fault current on distribution system. This paper focuses on analysis of steady state stability of $33 \mathrm{kV}$ power grid using load flow, contingency analysis and voltage stability (P-V Curve). The analysis is done by using industrial grade power software called Power System Simulation for Engineers (PSS/E). The power flow result showed that there are three generators generating out of limits. Contingency results showed that three transformer branches and three distribution branches are affected. There are nine weakest buses that violate contingency voltage deviation criterion and cannot withstand more load power when N-1-1 case in the branch of bus 8 to bus 28 is under outage.
\end{abstract}

\section{Keywords}

Load Flow, Contingency Analysis, PV Curve, Voltage Stability, Overload, Voltage Deviation Violation

\section{Introduction}

In Sabah grid, the power demand is increasing annually but the generated capacities is less than the power demand, especially in the east coast [1]. The current equipments in transmission system such as electricity cable are getting old and are found operated closer to their limits of stability and cannot withstand with increased power supply [2]. Due to these, the grid system is exposed to disturbances or contingencies which can cause system collapse and blackout. Sabah faced two major serious blackouts [1]. The most severe blackout happened in 2014 for 10 hours of state-wide blackout. The collapse is triggered by flashover which is from conductor of $132 \mathrm{KV}$ transmission line. Another one is blackout in the whole east coast due to outage of $275 \mathrm{KV}$ transmission line. 
As stated in Sabah grid Code [3], most of transmission lines, distribution and transformers fulfil N-1 contingency requirement, but in fact studies showed that there is no $\mathrm{N}-1$ contingency in aging existing transformer and existing line configuration [2]. Therefore, when N-1 contingency happens, overload conditions occur on those transformers, distribution and transmission lines.

Contingency analysis has been developed by [4] using sensitivity factors to approximate power flow on branches whereas voltage performance index is used by [5] to approximate the contingency voltage on a certain bus in a power system. For voltage stability part, [6] reviewed four commonly used voltage stability analysis tools which are $\mathrm{PV} / \mathrm{QV}$ curve analysis, $\mathrm{L}$ index, Modal analysis and V/Vo index. Authors have done comparison of accuracy results on IEEE bus power system.

This paper focuses on steady state stability for distribution level of power grid. Thus, $33 \mathrm{KV}$ Sandakan network of Sabah Grid System is chosen to simulate steady state stability which consists of load flow simulation, contingency simulation and $\mathrm{P}-\mathrm{V}$ curve. Contingency scenarios are created to test its overall steady state stability of the grid in terms of contingency voltage deviation violation and percentage overload. Moreover, $\mathrm{P}-\mathrm{V}$ analysis is performed to determine the weakest buses in the network. The process of analysing the stability can be daunting and challenging if the power network is highly complex, large size and non-linear. The process takes a lot of time in the calculations to access all the power variables and contingencies [7]. Therefore, a Power System Simulation for Engineers (PSS/E) software is utilized to perform all power flow computations in this steady state analysis.

\section{Existing N-1 Network}

The existing model of power system network shown in Figure 1 is modelled by using (PSS/E).This network is disconnected from the main grid power supply, especially the supply from $275 \mathrm{KV}$ transmission line. Therefore, in that case, the network itself is assumed as N-1 under outages of main grid and is considered as external N-1 condition. Date of bus names, Transformers, generators, loads and branches regarding powers and impedances are given in the tables at the Appendix.

The grid system has the following major components:

1) Buses: 34 (27 of them are connected)

2) Loads: 24 (22 of them are in service)

3) Branches: 40 (29 out of 32 distribution branches and 8 transformer branches are in service)

4) Fixed shunts: 6 ( 5 of them are in service)

5) Generators (machines): 8 (6 of them are in service)

\section{Load Flow Analysis}

Load flow analysis is used to calculate voltage, current flows, active and reactive 


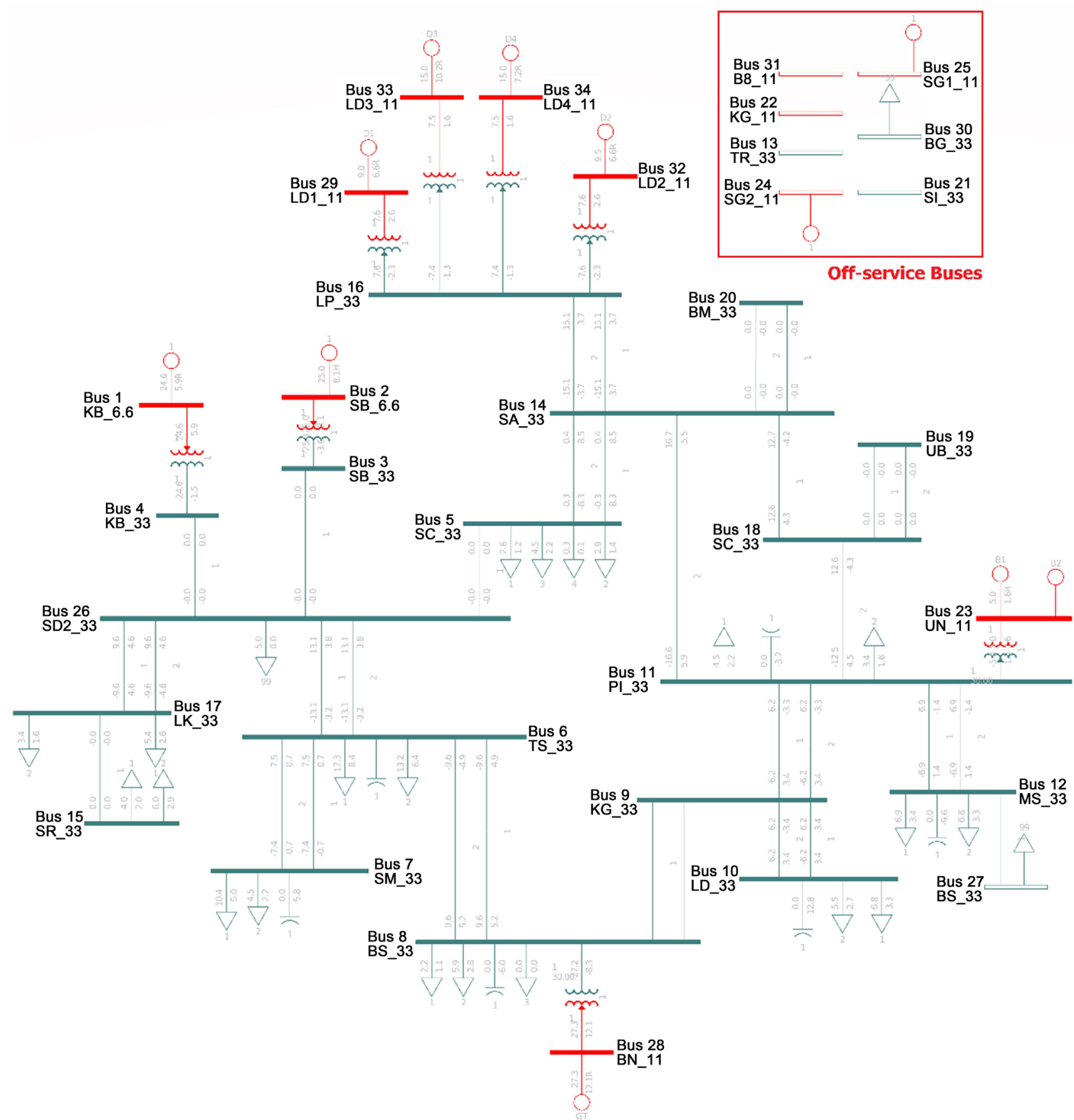

Figure 1. Existing power network drawn in PSS/E.

powers, power losses for generators, load and generator buses, distribution and transformer branches, and loads in the Power network. There are two types of solutions in PSS/E: Newton Raphson and Gauss Seidel load flows. Due to complexity and large number of buses in N-1 power network, Newton Raphson is chosen due to faster converging rate and repetitive complicated computation of Jacobian matrix and its minimal sensitivity. For contingency cases, Fixed Slope Decoupled load flow which is part of Newton Raphson created by Siemens Company is chosen as it performs better in difficult and complicated cases 
compared to other types of methods.

There are four power elements that load flow used to calculate. These are:

1) Generators (swing buses): generated active and reactive power flows

2) Distribution and transformer branches: current flows, active and reactive power flows, percentage voltage drop, power factor, and power losses.

3) Buses (load buses and generator buses): bus voltage, active and reactive power flows, and current flows.

4) Loads: active and reactive power flows, current flows, and percentage loading.

Table 1 shows the power flow results of generated active power and reactive power for each in-service generating unit which act as swing bus. $\mathrm{P}_{\max }$ and $\mathrm{P}_{\min }$ are the maximum and minimum generated capacity for each generator. Same goes to $\mathrm{Q}_{\min }$ and $\mathrm{Q}_{\max }$ which represent reactive power capacity. With respect to PGen, all generators generated within their active power and reactive power limits except for generators named KB_6.6, SB_6.6, and BN_11.

Table 2 shows the total generated power by all generators before and after the

Table 1. Generators results.

\begin{tabular}{ccccccccc}
\hline Bus No. & Bus Name & Base kV & $\begin{array}{c}\text { PGen } \\
(\mathrm{MW})\end{array}$ & $\begin{array}{c}\mathrm{P}_{\max } \\
(\mathrm{MW})\end{array}$ & $\begin{array}{c}\mathrm{P}_{\min } \\
(\mathrm{MW})\end{array}$ & $\begin{array}{c}\text { QGen } \\
(\mathrm{MVAr})\end{array}$ & $\begin{array}{c}\mathrm{Q}_{\max } \\
\text { (MVAr) }\end{array}$ & $\begin{array}{c}\mathrm{Q}_{\min } \\
(\mathrm{MVAr})\end{array}$ \\
\hline 1 & KB_6.6 & 6.6000 & 24.6 & 10.0 & 0.0 & 5.9 & 7.3 & 0.5 \\
2 & SB_6.6 & 6.6000 & 25.0 & 10.0 & 0.0 & 8.1 & 7.3 & 0.5 \\
23 & GN_11 & 11.000 & 5.0 & 37.0 & 20.0 & 1.6 & 24.8 & -14.7 \\
28 & BN_11 & 11.000 & 27.3 & 20.0 & 0.0 & 12.1 & 21.2 & -15.2 \\
32 & LD1_11 & 11.000 & 7.6 & 15.0 & 8.0 & 2.6 & 11.4 & -8.5 \\
33 & LD2_11 & 11.000 & 7.6 & 15.0 & 8.0 & 2.6 & 11.4 & -8.5 \\
34 & LD3_11 & 11.000 & 7.5 & 15.0 & 8.0 & 1.6 & 11.4 & -8.5 \\
\hline
\end{tabular}

Table 2. Total generated power in sandakan before and after N-1 outage.

\begin{tabular}{cccccc}
\hline Bus No. & Bus Name & Base kV & $\begin{array}{c}\text { PGen (MW) } \\
\text { (After Outage) }\end{array}$ & $\begin{array}{c}\text { PGen (MW) } \\
\text { (Before Outage) }\end{array}$ & $\begin{array}{c}\text { Active Power } \\
\text { Capacity (MW) }\end{array}$ \\
\hline 1 & KB_6.6 & 6.6000 & 24.6 & 10.00 & 10.0 \\
2 & SB_6.6 & 6.6000 & 25.0 & 10.00 & 10.0 \\
23 & GN_11 & 11.000 & 5.0 & 14.76 & 37.0 \\
28 & BN_11 & 11.000 & 27.3 & 15.00 & 20.0 \\
29 & LD1_11 & 11.000 & 7.6 & 9.50 & 15.0 \\
32 & LD2_11 & 11.000 & 7.6 & 9.50 & 15.0 \\
33 & LD3_11 & 11.000 & 7.5 & 15.00 & 15.0 \\
34 & LD4_11 & 11.000 & 7.5 & 15.00 & 15.0 \\
& TOTAL & & 112.10 & 98.76 & 137.00
\end{tabular}


main supply outage from $275 \mathrm{KV}$ transmission line with respect to the total generated capacity. The table shows that the power demand increase by 13.34 MW from 98.76 MW after the outage, but they are within the total generated capacity.

Table 3 shows the load flow results for all in-service branches (transformer and distribution). Note: DB is distribution branch, TB is transformer branch. Transformer branches are found higher active and reactive power losses, higher percent of voltage drop, higher current flows and higher active and reactive power flows than that in distribution branches. Only transformer branches have higher loadings problem compared to distribution branches. For distribution branches, DB10_1 is recorded with highest power losses. For transformer branches, TB3 is recorded with highest reactive power loss and TB5 and TB6 share the highest active power losses. TB2 is recorded with highest percent of voltage drop among all branches, followed by DB2_1 and DB2_2. DB14_1, DB14_2, DB17_1 and DB17_2 are recorded with zero among all variables.

Table 4 and Table 5 show the load flow results for all in-service buses. Load buses are represented by bus code 1 while generator buses are represented by bus code 2. UB_33 and BM_33 are recoded zero in active and reactive power flows and current flows due to no loads connected to them. Generator buses are recorded higher current flows compared to load buses. All bus voltages are within contingency voltage range stated by Distribution Code of Energy Commission. The voltage range is from $0.9 \mathrm{pu}$ to $1.1 \mathrm{pu}$. That means all bus voltages are safe and secure under $\mathrm{N}-1$ case which is disconnected from main grid supply.

This load flow analysis shows that all bus voltages are slightly higher than $100 \%$ and 2 load buses are overloaded as well as 3 generators generating out of limits.

\section{Contingency Analysis}

To compute the branch power flows after certain level of outage, contingency sensitivity factors are used to approximate the change in line flows and the changes in generation in a power system. It is one of fastest way to calculate possible overloads in a power system network. The main two sensitivity factors are Generation Shift Factors (GSF) and Line Outage Distribution Factors (LODF).

For GSF part, the generation factor is defined as changes in power flow in particular line when a change in power generation at reference bus occurs.

Generation shift factors,

$$
\alpha_{l i}=\frac{\Delta P F_{l}}{\Delta P_{G i}}
$$

where $\Delta P F_{l}=$ changes in power flow on $I^{\text {th }}$ line

$\Delta P_{G i}=$ changes in generation which takes place on $I^{\text {th }}$ bus

For LODF, the line outage distribution factor is defined as the change in power flow on $i^{\text {th }}$ line during pre-contingency line flow on $l^{\text {th }}$ line.

Line outage distribution factors, 
Table 3. Distribution and transformer branch results.

\begin{tabular}{|c|c|c|c|c|c|}
\hline Branches & MW Flows & MVAr Flows & $\%$ Voltage Drop & kW Losses & kVAr Losses \\
\hline DB1_1 & 13.606 & 3.741 & 0 & 0.002 & 0.196 \\
\hline DB1_2 & 13.3 & 1.644 & 0 & 0.002 & 0.176 \\
\hline DB2_1 & 12.004 & 6.544 & 2.25 & 30.998 & 557 \\
\hline DB2_2 & 12.004 & 6.544 & 2.25 & 30.998 & 557 \\
\hline DB3 & 13.752 & 7.036 & 0 & 0.002 & 0.234 \\
\hline DB4_1 & 7.457 & 0.646 & 0.22 & 13.641 & 36.767 \\
\hline DB4__2 & 7.457 & 0.646 & 0.22 & 13.641 & 36.767 \\
\hline DB5_1 & 9.328 & 4.194 & 0.95 & 11.233 & 195 \\
\hline DB5_2 & 9.328 & 4.194 & 0.95 & 11.233 & 195 \\
\hline DB6_1 & 13.406 & 1.646 & 0.75 & 35.109 & 632 \\
\hline DB6_2 & 13.406 & 1.646 & 0.75 & 35.109 & 632 \\
\hline DB7_1 & 6.187 & -3.415 & 0.08 & 9.547 & 29.333 \\
\hline DB7_2 & 6.187 & -3.415 & 0.08 & 9.547 & 29.333 \\
\hline DB8_1 & 6.225 & -3.339 & 0.05 & 27.673 & 47.071 \\
\hline DB8__2 & 6.225 & -3.339 & 0.05 & 27.673 & 47.071 \\
\hline DB9_1 & 6.907 & -1.432 & 0.08 & 9.47 & 15.861 \\
\hline DB9_2 & 6.907 & -1.432 & 0.08 & 9.47 & 15.861 \\
\hline DB10_1 & 12.132 & -5.175 & 0.07 & 83.315 & 225 \\
\hline DB11_1 & 9.181 & -3.916 & 0.04 & 30.672 & 82.668 \\
\hline DB12_1 & 22.751 & 2.229 & 0.09 & 16.57 & 34.142 \\
\hline DB12_2 & 22.751 & 2.229 & 0.09 & 16.57 & 34.142 \\
\hline DB13_1 & 9.212 & -3.833 & 0.03 & 32.376 & 87.261 \\
\hline DB14_1 & 0 & 0 & 0 & 0 & 0 \\
\hline DB14_2 & 0 & 0 & 0 & 0 & 0 \\
\hline DB15_1 & 10.072 & 4.878 & 0 & 0.001 & 0.123 \\
\hline DB16_1 & 9.423 & 4.565 & 0.01 & 0.393 & 1.058 \\
\hline DB16_2 & 9.423 & 4.565 & 0.01 & 0.393 & 1.058 \\
\hline DB17_1 & 0 & 0 & 0 & 0 & 0 \\
\hline DB17_2 & 0 & 0 & 0 & 0 & 0 \\
\hline TB1 & 13.368 & 2.902 & 2.09 & 67.639 & 1258 \\
\hline TB2 & 13.68 & 5.136 & 3.59 & 74.983 & 1395 \\
\hline TB3 & 26.747 & 9.69 & 3.8 & 29.418 & 3530 \\
\hline TB4 & 12.879 & 1.094 & 0.76 & 49.758 & 925 \\
\hline TB5 & 11.549 & 2.247 & 1.65 & 81.776 & 629 \\
\hline TB6 & 11.549 & 2.247 & 1.65 & 81.776 & 629 \\
\hline TB7 & 11.361 & 1.21 & 1.15 & 77.846 & 599 \\
\hline TB8 & 11.361 & 1.21 & 1.15 & 77.846 & 599 \\
\hline
\end{tabular}


Table 4. Load flows results for all in-service buses.

\begin{tabular}{|c|c|c|c|c|c|}
\hline Buses & Bus Code & Bus Voltage (pu) & MW Loading & MVAr Loading & Amp Loading \\
\hline BM_33 & 1 & 1.0316 & 0 & 0 & 0 \\
\hline BN_11 & 2 & 1.049 & 26.747 & 9.69 & 1423 \\
\hline BS_33 & 1 & 1.011 & 26.718 & 12.293 & 508.9 \\
\hline GN_11 & 2 & 1.04 & 12.879 & 1.094 & 652.3 \\
\hline KB_6.6 & 2 & 1.03 & 13.368 & 2.902 & 1162 \\
\hline KB_33 & 1 & 1.0091 & 13.3 & 1.644 & 232.4 \\
\hline KG_33 & 1 & 1.0329 & 12.394 & 6.772 & 239.2 \\
\hline LD1_11 & 2 & 1.049 & 11.549 & 2.247 & 588.7 \\
\hline LD2_11 & 2 & 1.049 & 11.549 & 2.247 & 588.7 \\
\hline LD3_11 & 2 & 1.044 & 11.361 & 1.21 & 574.4 \\
\hline LD4_11 & 2 & 1.044 & 11.361 & 1.21 & 574.4 \\
\hline LD_33 & 1 & 1.0337 & 12.375 & 12.823 & 301.6 \\
\hline LK_33 & 1 & 1.009 & 18.845 & 9.127 & 363.1 \\
\hline LP_33 & 1 & 1.0325 & 45.501 & 4.459 & 774.7 \\
\hline MS_33 & 1 & 1.0316 & 13.796 & 9.578 & 284.8 \\
\hline PI_33 & 1 & 1.0324 & 34.143 & 12.907 & 618.6 \\
\hline SA_33 & 1 & 1.0316 & 45.468 & 13.087 & 802.4 \\
\hline SB_3.3 & 1 & 1.0091 & 13.606 & 3.741 & 244.6 \\
\hline SB_6.6 & 2 & 1.045 & 13.68 & 5.136 & 1223 \\
\hline SC_33 & 1 & 1.032 & 9.212 & 3.833 & 169.2 \\
\hline SD2_33 & 1 & 1.0091 & 45.658 & 12.421 & 820.4 \\
\hline SD_33 & 1 & 1.0091 & 23.946 & 11.973 & 464.2 \\
\hline SM_33 & 1 & 0.9993 & 14.887 & 7.21 & 289.6 \\
\hline SR_33 & 1 & 1.009 & 10.072 & 4.878 & 194 \\
\hline TS_33 & 1 & 1.0016 & 45.375 & 16.043 & 840.7 \\
\hline UB_33 & 1 & 1.032 & 0 & 0 & 0 \\
\hline
\end{tabular}

$$
d_{l i}=\frac{\Delta P F_{l}}{P_{i}^{o}}
$$

where $\Delta P F_{l}=$ changes in power flow on $l^{\text {th }}$ line

$P_{i}^{o}=$ Power line flow on $t^{\text {th }}$ line before contingency of $I^{\text {th }}$ line

In PSS/E software, the process of performing contingency analysis is done automatically and comprehensively without manually tripping each line. Before carrying out N-1 contingency analysis, three types of files are created. They are ${ }^{*}$ mon.file, ${ }^{*}$ sub.file and ${ }^{*}$ con.file. Each file is described in Table 6 . Figure 2 shows the process of creating these files. 
Table 5. Load flow results for all in-service loads.

\begin{tabular}{|c|c|c|c|c|c|c|}
\hline Load Buses & Id & MW Flows (kW) & MVAr Flows (kVAr) & Current Flows & $\% \mathrm{PF}$ & \% Loading \\
\hline SD_33 & 1 & 2573 & 1246 & 49.57 & 90 & 99.1 \\
\hline SD_33 & 2 & 2879 & 1395 & 55.47 & 89.99 & 99.1 \\
\hline SD_33 & 3 & 4460 & 2160 & 85.92 & 90 & 99.1 \\
\hline SD_33 & 4 & 282 & 136 & 5.428 & 90.07 & 99.1 \\
\hline TS_33 & 1 & 17,289 & 8373 & 335.6 & 90 & 99.8 \\
\hline TS_33 & 2 & 13,172 & 6379 & 255.7 & 90 & 99.8 \\
\hline SM_33 & 1 & 10,415 & 5044 & 202.6 & 90 & 100.1 \\
\hline SM_33 & 2 & 4472 & 2166 & 86.99 & 90 & 100.1 \\
\hline BS_33 & 1 & 2181 & 1056 & 41.93 & 90 & 98.9 \\
\hline BS_33 & 2 & 5881 & 2848 & 113.1 & 90 & 98.9 \\
\hline LD_33 & 1 & 6849 & 3317 & 128.8 & 90 & 96.7 \\
\hline LD_33 & 2 & 5526 & 2676 & 103.9 & 90 & 96.7 \\
\hline PI_33 & 1 & 4497 & 2178 & 84.68 & 90 & 96.9 \\
\hline PI_33 & 2 & 3382 & 1638 & 63.68 & 90 & 96.9 \\
\hline MS_33 & 1 & 6947 & 3365 & 130.9 & 90 & 96.9 \\
\hline MS_33 & 2 & 6849 & 3317 & 129.1 & 90 & 96.9 \\
\hline SR_33 & 1 & 4031 & 1952 & 77.66 & 90 & 99.1 \\
\hline SR_33 & 2 & 6041 & 2926 & 116.4 & 90 & 99.1 \\
\hline LK_33 & 1 & 5416 & 2623 & 104.3 & 90 & 99.1 \\
\hline LK_33 & 2 & 3357 & 1626 & 64.68 & 90 & 99.1 \\
\hline SD2_33 & 1 & -5000 & 0 & 86.69 & 100 & 99.1 \\
\hline TS_33 & 1 & 0 & -6019 & 105.1 & 0 & - \\
\hline SM_33 & 1 & 0 & -5992 & 104.9 & 0 & - \\
\hline BS_33 & 1 & 0 & -6133 & 106.1 & 0 & - \\
\hline LD_33 & 1 & 0 & -12823 & 217 & 0 & - \\
\hline PI_33 & 3 & 0 & -3197 & 54.18 & 0 & - \\
\hline MS_33 & 3 & 0 & -9578 & 162.4 & 0 & - \\
\hline
\end{tabular}

Table 6. Three types of PSS/E files with descriptions.

\begin{tabular}{cl}
\hline File Type & \multicolumn{1}{c}{ Description } \\
\hline \multirow{*}{*}{ mon.file } & $\begin{array}{l}\text { It informs load flow simulator the branches needed to be monitored when N-1 } \\
\text { contingency happens. It also monitors and records the bus voltages within specific } \\
\text { ranges or outside the range. }\end{array}$ \\
${ }^{*}$ sub.file & $\begin{array}{l}\text { It tells load flow analysis to consider and perform at specific zone. It includes all } \\
\text { involved power network elements in the case study. }\end{array}$ \\
& $\begin{array}{l}\text { It is used to trip line or power elements to create contingency scenarios. Three types } \\
\text { of contingencies: N-0 (system intact), N-1 (single power element outage) and N-2 } \\
\text { (two power elements outage). In this case, N-1 is chosen. }\end{array}$ \\
\hline
\end{tabular}




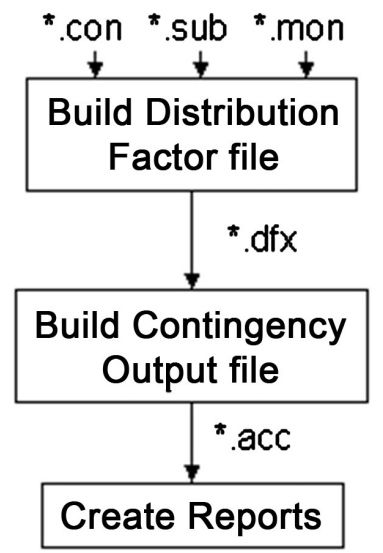

Figure 2. Process of creating these files.

Before doing any $\mathrm{N}-1$ contingency analysis, it is compulsory to comply the contingency voltage range is set within $\pm 10 \%$ of nominal voltage at steady state level for $33 \mathrm{kV}$ distribution network. Since the nominal voltage is $1.0 \mathrm{pu}$, therefore the range is from $0.9 \mathrm{pu}$ to $1.1 \mathrm{pu}$. Besides, there are two types of contingency case analyzed as follows:

1) External contingency $(\mathrm{N}-1)$ : is the power network cut off supply from main grid

2) Internal contingency (N-1-1): is another contingency happens after external contingency occurred

Branch flows and overload condition are determined for affected branches in every contingency case. Also, determines the buses that violate the contingency voltage deviation criterion which is the changes in voltage cannot rise more than $0.06 \mathrm{pu}$ and drop more than $0.03 \mathrm{pu}$.

From Table 7, transformer branches which are marked in italic are recorded higher than that in distribution branches. The most severe overload cases happen on the transformer branches near to SB_6.6 and KB_6.6 generators. This is because the lost generation from incomer main grid is supplied by these two supplies, causing them to generate more power demand.

In the contingency analysis, all branches except six branches are considered safe and remained unaffected throughout all contingency cases (N-1-1 and N-1). Table 8 shows that the list of 31 unaffected branches out of 37 branches involved in contingency analysis. The branches highlighted in italic are transformer branches and the rest are distribution branches.

There is no contingency voltage deviation violation report in all contingency cases except for case when outage of transformer branch bus 8 to bus 28. The bus that cannot withstand $\mathrm{N}-1$ or N-1-1 is if they violate the voltage deviation criterion. The violation case can be shown visually in Figure 3. The affected buses highlighted in red are the buses that cannot withstand N-1. The transformer branch outage is highlighted in black. Table 9 shows the affected buses during the contingency case named SINGLE 8-28 with their respective contingency voltage, initial voltage, and the voltage deviation limits. 
Table 7. List of affected branches with respective total number of involved cases and overload percent.

\begin{tabular}{|c|c|c|c|c|c|c|}
\hline \multicolumn{5}{|c|}{ Affected Branches } & \multirow{3}{*}{$\begin{array}{l}\text { No. of Cases Involved } \\
\text { from Total } 38 \text { contingency Cases }\end{array}$} & \multirow{3}{*}{$\begin{array}{l}\text { Overload Percent } \\
\text { Ranges (\%) }\end{array}$} \\
\hline \multicolumn{2}{|c|}{ From Bus } & \multicolumn{2}{|c|}{ To Bus } & \multirow{2}{*}{ Id } & & \\
\hline No & Name & No & Name & & & \\
\hline 1 & $K B \_6.6$ & 4 & $K B \_33$ & 1 & 38 & $174.0-228.1$ \\
\hline 2 & $S B \_6.6$ & 3 & $S B \_33$ & 1 & 38 & $173.4-238.3$ \\
\hline 6 & TS_33 & 8 & BS_33 & 2 & 1 & 110.2 \\
\hline 8 & BS_33 & 28 & $B N \_11$ & 1 & 38 & $110.5-142.0$ \\
\hline 14 & SA_33 & 16 & LP_33 & 1 & 8 & $101.8-165.0$ \\
\hline 14 & SA_33 & 16 & LP_33 & 2 & 8 & $101.8-165.0$ \\
\hline
\end{tabular}

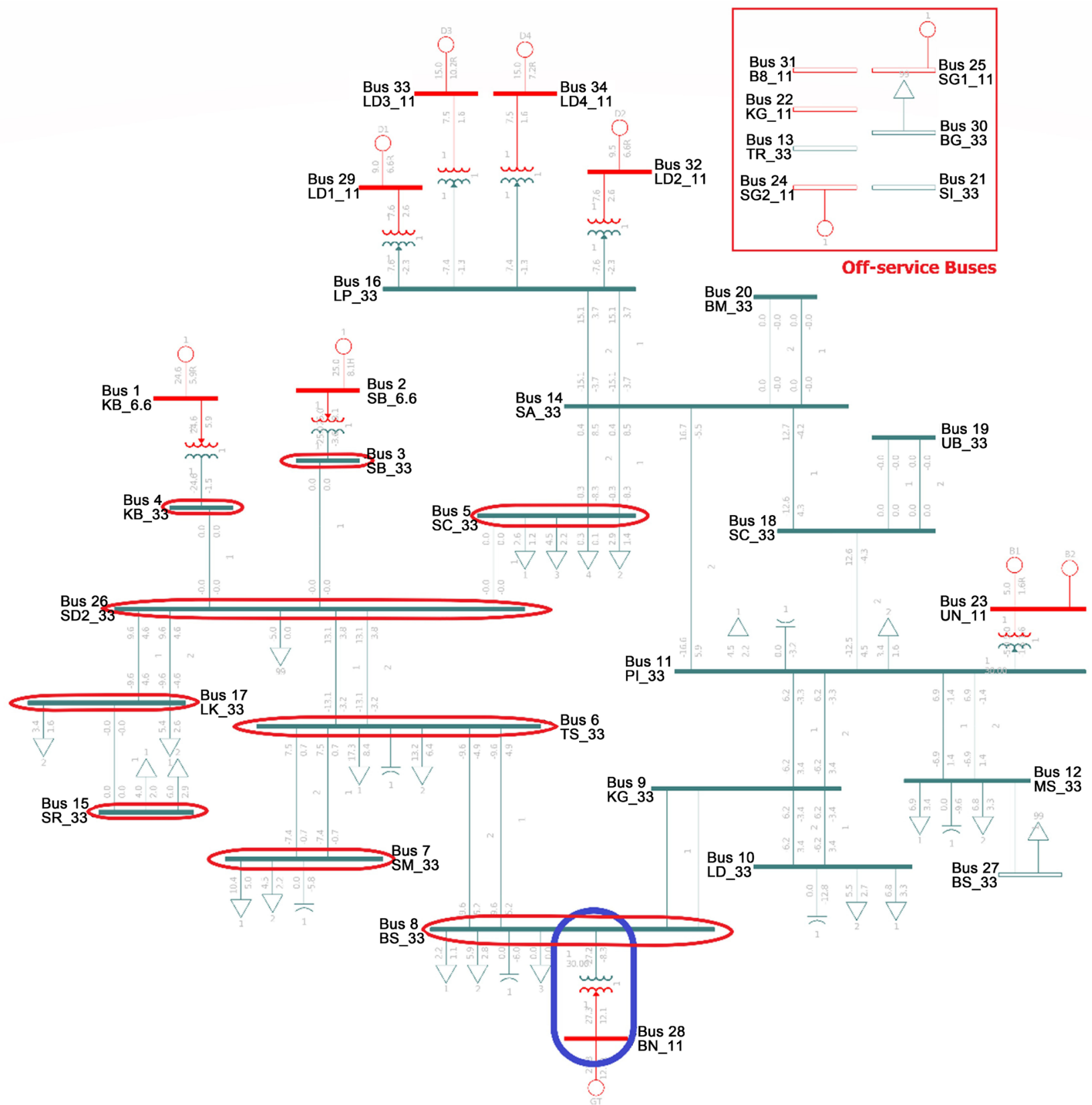

Figure 3. N-1-1 case with affected buses when outage of transformer branch from bus 8 to bus 28 . 
Table 8. List of unaffected branches throughout all contingency cases (N-1 and N-1-1 cases).

\begin{tabular}{|c|c|c|c|c|}
\hline \multicolumn{5}{|c|}{ Unaffected Branches } \\
\hline \multicolumn{2}{|c|}{ From Bus } & \multicolumn{2}{|c|}{ To Bus } & \multirow{2}{*}{ Id } \\
\hline No. & Name & No. & Name & \\
\hline 16 & $L P \_33$ & 29 & $L D 1 \_11$ & 1 \\
\hline 16 & $L P \_33$ & 32 & $L D 2 \_11$ & 1 \\
\hline 16 & $L P \_33$ & 33 & $L D 3 \_11$ & 1 \\
\hline 16 & $L P \_33$ & 34 & $L D 4 \_11$ & 1 \\
\hline 11 & PI_33 & 23 & $G N \_11$ & 1 \\
\hline 3 & SB_33 & 26 & SD2_33 & 1 \\
\hline 4 & KB_33 & 26 & SD2_33 & 2 \\
\hline 5 & SD_33 & 14 & SA_33 & 1 \\
\hline 5 & SD_33 & 14 & SA_33 & 2 \\
\hline 5 & SD_33 & 26 & SD2_33 & 1 \\
\hline 6 & TS_33 & 7 & SM_33 & 1 \\
\hline 6 & TS_33 & 7 & SM_33 & 2 \\
\hline 6 & TS_33 & 8 & BS_33 & 1 \\
\hline 6 & TS_33 & 8 & BS_33 & 2 \\
\hline 6 & TS_33 & 26 & $\mathrm{SD} 2 \_33$ & 1 \\
\hline 6 & TS_33 & 26 & SD2_33 & 2 \\
\hline 9 & KG_33 & 10 & LD_33 & 1 \\
\hline 9 & KG_33 & 10 & LD_33 & 2 \\
\hline 9 & KG_33 & 11 & PI_33 & 1 \\
\hline 9 & KG_33 & 11 & PI_33 & 2 \\
\hline 11 & PI_33 & 12 & MS_33 & 1 \\
\hline 11 & PI_33 & 12 & MS_33 & 2 \\
\hline 11 & PI_33 & 14 & SA_33 & 1 \\
\hline 11 & PI_33 & 18 & SC_33 & 1 \\
\hline 14 & SA_33 & 16 & LP_33 & 1 \\
\hline 14 & SA_33 & 16 & LP_33 & 2 \\
\hline 14 & SA_33 & 18 & SC_33 & 1 \\
\hline 14 & SA_33 & 20 & BM_33 & 1 \\
\hline 14 & SA_33 & 20 & BM_33 & 2 \\
\hline 15 & SR_33 & 17 & LK_33 & 1 \\
\hline 17 & LK_33 & 26 & SD2_33 & 1 \\
\hline 17 & LK_33 & 26 & SD2_33 & 2 \\
\hline 18 & SC_33 & 19 & UB_33 & 1 \\
\hline 18 & SC_33 & 19 & UB_33 & 2 \\
\hline
\end{tabular}


Contingency results showed 3 transformer branches and 2 distribution branches are affected.

\section{P-V (Load Power-Load Voltage) Curve Analysis}

P-V curve is commonly used as voltage stability analysis tool to analyze maximum additional load power that a bus can sustain before its voltage collapses, after the load power exceeds its power limits. Figure 4 shows a simple P-V curve. When load power exceeds the power limit of a bus, the bus voltage will start to drop until reaching the critical point, which is voltage collapse point when the bus reaches the maximum additional power. PSS/E is able to simulate different $\mathrm{P}-\mathrm{V}$ curve for different level of contingency. So, in this paper, P-V curve is simulated for external contingency and internal contingency cases for all 26 in-service buses. The maximum additional power transfer and voltage collapse point are recorded for each buses in every contingency cases.

All buses are simulated with P-V curves for every contingency case. Thus, 988 (38 contingency cases X 26 buses) P-V curves are simulated. Table 10 shows the list of number of contingency cases with the overall maximum additional power transfer among all buses. Among 38 contingency cases, 15 of them are recorded with the highest maximum additional power transfer with $312.50 \mathrm{MW}$, followed

Table 9. Contingency voltage deviation violation reports.

\begin{tabular}{ccccccc}
\hline \multicolumn{1}{c}{ Contingency Label } & Bus No. & $\begin{array}{c}\text { Bus } \\
\text { Name }\end{array}$ & $\begin{array}{c}\text { V-Cont } \\
(\mathrm{pu})\end{array}$ & $\begin{array}{c}\text { V-Init } \\
(\mathrm{pu})\end{array}$ & $\begin{array}{c}\text { V-Rise } \\
(\mathrm{pu})\end{array}$ & $\begin{array}{c}\text { V-Drop } \\
(\mathrm{pu})\end{array}$ \\
\hline DEVIATION SINGLE 8-28 & 3 & SB_33 & 0.97276 & 1.00406 & 0.06000 & 0.03000 \\
DEVIATION SINGLE 8-28 & 4 & KB_33 & 0.97276 & 1.00406 & 0.06000 & 0.03000 \\
DEVIATION SINGLE 8-28 & 5 & SD_33 & 0.97276 & 1.00406 & 0.06000 & 0.03000 \\
DEVIATION SINGLE 8-28 & 6 & TS_33 & 0.93054 & 0.98853 & 0.06000 & 0.03000 \\
DEVIATION SINGLE 8-28 & 7 & SM_33 & 0.92785 & 0.98622 & 0.06000 & 0.03000 \\
DEVIATION SINGLE 8-28 & 8 & BS_33 & 0.93149 & 1.00015 & 0.06000 & 0.03000 \\
DEVIATION SINGLE 8-28 & 15 & SR_33 & 0.97268 & 1.00398 & 0.06000 & 0.03000 \\
DEVIATION SINGLE 8-28 & 17 & LK_33 & 0.97268 & 1.00398 & 0.06000 & 0.03000 \\
DEVIATION SINGLE 8-28 & 26 & SD2_33 & 0.97276 & 1.00406 & 0.06000 & 0.03000 \\
\hline
\end{tabular}

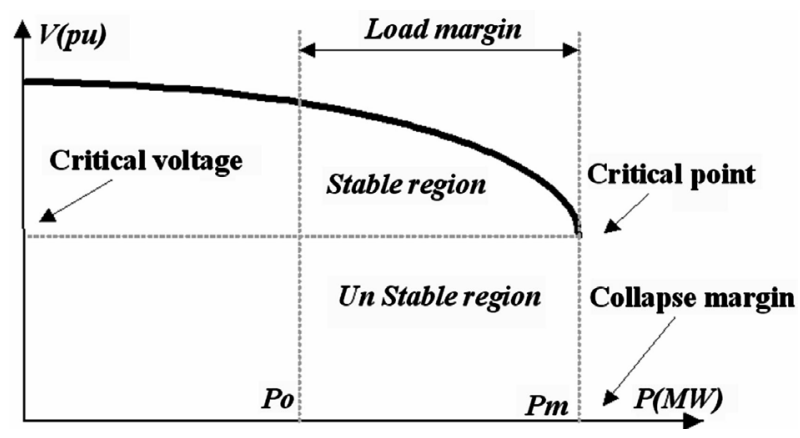

Figure 4. PV curve. 
by 6 cases with $306.25 \mathrm{MW}$ and 5 cases with $287.50 \mathrm{MW}$. The only one case with the lowest maximum additional power transfer (143.75 MW) happened when outage of transformer branch from bus 8 to bus 28. That means all buses can only withstand incremental power transfer up to $143.75 \mathrm{MW}$ when this outage happens. That is why this case has only voltage violation cases, referring to Table 8. They cannot withstand higher power flows compared to other cases.

Among all P-V curves, almost all buses except generator buses have their voltage collapse point at below $0.9 \mathrm{pu}$. That is not reasonable that the steady state operating voltage is within $10 \%$ of the nominal voltage, from $0.9 \mathrm{pu}$ to $1.1 \mathrm{pu}$. Since the weakest case is SINGLE 8-28 (1), in order to determine weakest buses, the maximum incremental power transfer at $0.9 \mathrm{pu}$ of the nominal voltage is determined for each bus. Any voltage which is outside of the tolerance is not acceptable. Figure 5 shows the finding of maximum additional power transfer at

Table 10. List of number of contingency cases and the maximum additional power transfer.

\begin{tabular}{cc}
\hline No. of contingency cases & Maximum Additional Power Transfer (MW) \\
\hline 1 & 143.75 \\
1 & 218.75 \\
2 & 243.75 \\
4 & 256.25 \\
2 & 268.75 \\
5 & 287.50 \\
2 & 293.75 \\
6 & 306.25 \\
15 & 312.50 \\
\hline
\end{tabular}

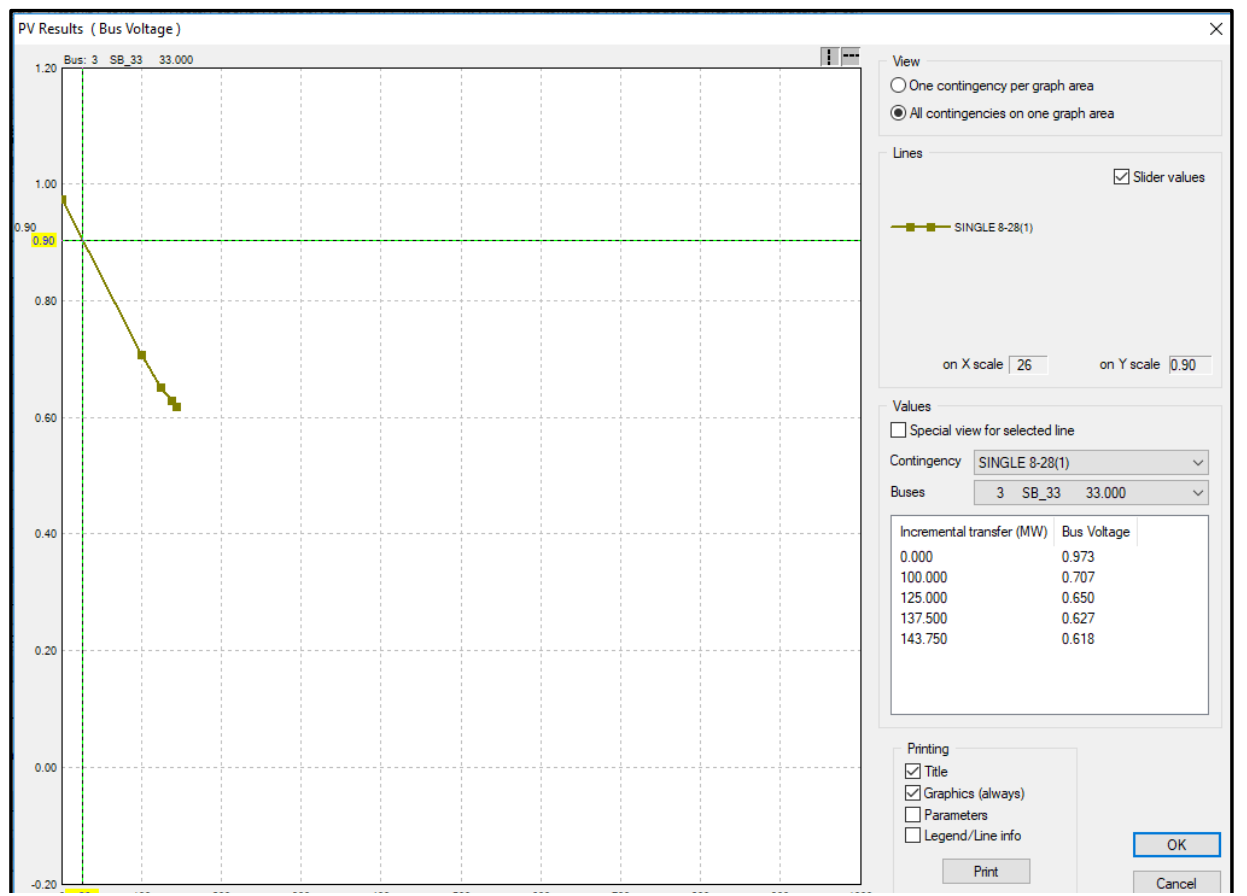

Figure 5. Maximum additional power transfer at 0.9 pu in PV curve. 
$0.9 \mathrm{pu}$. Table 11 shows the maximum additional power transfer at $0.9 \mathrm{pu}$ for each bus with respective voltage collapse point at contingency case named SINGLE 8-28.

From Table 11, the generator buses (KB_6.6, SB_6.6, BN_11, GN_11, LD1_11, LD2_11, LD3_11 and LD4_11) have maintained constant bus voltage along all incremental power transfer. This is because no losses involved when the generators generate the output voltage to the nearest buses. The loss will be very small. Any bus that withstand below $50 \%$ of the $143.75 \mathrm{MW}$ is considered as weakest buses. Therefore, the weakest buses are SB_33, KB_33, SD_33, TS_33,

Table 11. List of all buses with their respective maximum additional power transfer at 0.9 puin weakest contingency case (Single 8-28).

\begin{tabular}{|c|c|c|c|}
\hline Bus No. & Bus Name & $\begin{array}{l}\text { Maximum Incremental Power Flow } \\
(\mathrm{MW}) \text { at } 0.9 \mathrm{pu}\end{array}$ & $\begin{array}{l}\text { Voltage Collapse } \\
\text { Point (pu) }\end{array}$ \\
\hline 1 & KB_6.6 & 143.75 & 1.030 \\
\hline 2 & SB_6.6 & 143.75 & 1.045 \\
\hline 9 & KG_33 & 80 & 0.812 \\
\hline 10 & LD_33 & 80 & 0.807 \\
\hline 11 & PI_33 & 83 & 0.827 \\
\hline 12 & MS_33 & 86 & 0.821 \\
\hline 14 & SA_33 & 92 & 0.843 \\
\hline 28 & BN_11 & 143.75 & 1.049 \\
\hline 29 & LD1_11 & 143.75 & 1.049 \\
\hline 32 & LD2_11 & 143.75 & 1.049 \\
\hline 33 & LD3_11 & 143.75 & 1.044 \\
\hline 34 & LD4_11 & 143.75 & 1.044 \\
\hline 18 & SC_33 & 91 & 0.834 \\
\hline 19 & UB_33 & 91 & 0.834 \\
\hline 20 & BM_33 & 92 & 0.843 \\
\hline 23 & GN_11 & 143.75 & 1.040 \\
\hline 16 & LP_33 & 98 & 0.850 \\
\hline 3 & $S B \_33$ & 26 & 0.618 \\
\hline 4 & $K B \_33$ & 26 & 0.618 \\
\hline 5 & $S D \_33$ & 26 & 0.618 \\
\hline 6 & $T S \_33$ & 8 & 0.349 \\
\hline 7 & $S M \_33$ & 6 & 0.334 \\
\hline 8 & $B S \_33$ & 8 & 0.333 \\
\hline 15 & $S R \_33$ & 29 & 0.618 \\
\hline 17 & $L K \_33$ & 29 & 0.618 \\
\hline 26 & $S D 2 \_33$ & 27 & 0.618 \\
\hline
\end{tabular}


SM_33, BS_33, SR_33, LK_33, and SD2_33. The results from P-V actually correlate with the Contingency Voltage Violation results shown in Table 9.

\section{Conclusions}

Sandakan power network has serious overload condition on generating units compared to other distribution lines. This paper shows that 3 generators out of 8 are generating out of the limits. For all loads, a vast majority of loads are marginally overload. There are 9 weakest buses determined at weakest N-1-1 contingency case via P-V curve and Contingency analysis. The buses are found dropped out of the contingency voltage deviation criterion and can withstand smaller power transfer after the power exceeds their bus power limit.

Contingency analysis is a very important and useful tool in planning the unplanned electrical outages. It can predict the future power system conditions under outages. It evaluates how many those buses survive under outages and those didn't. In this case, PSS/E is able to perform contingency analysis within seconds and provide with accurate results. To improve its stability, two types of FACTS devices are recommended: UPFC and STATCOM. UPFC is used to compensate power flows to reduce overload condition whereas STATCOM is used to maintain bus voltage for better voltage profile.

\section{References}

[1] (2015) Sabah Electricity Outlook 2015. Energy Commission Malaysia, 1-60.

[2] Songkin, M., Barsoum, N.N., Wong, F. and Lim, P.Y. (2017) A Study on Sabah Grid System Stability. 2017 IEEE 2nd International Conference on Automatic Control and Intelligent Systems (I2CACIS 2017), 207-212.

[3] Grid Code for Sabah and Labuan (Amendments) 2017 (2017) Energy Commission Malaysia (Suruhanjaya Tenaga Malaysia). 1-206.

[4] Satyanarayana, B., Deepak, J. and Khyati, D. (2016) Contingency Analysis of Power System by Using Voltage and Active Power Performance Index. 1 st IEEE International Conference on Power Electronics, Intelligent Control and Energy Systems (ICPEICES), 1-5.

[5] Roman, V. and Lucie, N. (2015) Sensitivity Factors for Contingency Analysis. Institute of Electrical and Electronics Engineering (IEEE), 1-5.

[6] Reis, C., Andrade, A. and Maciel, F.P. (2009) Voltage Stability Analysis of Electrical Power System. Institute of Electrical and Electronics Engineering (IEEE), 244-248.

[7] Barsoum, N., Asok, C.B., SzuKwong, D.T. and Kit, C.G.T. (2017) Effect of Distributed Generators on Stability in a limited bus Power Grid System. Journal of Power and Energy Engineering, Scientific Research Publishing, 5, 74-91. 


\section{Appendix}

Table A1. Buses Data Used in PSS/E.

\begin{tabular}{|c|c|c|c|c|c|}
\hline Bus No. & Bus Name & Bus Code & Base $\mathrm{kV}$ & Voltage (pu) & Angle (deg) \\
\hline 1 & KB_6.6 & -2 & 6.6 & 1.0085 & -15.28 \\
\hline 2 & SB_6.6 & -2 & 6.6 & 1.0085 & -15.28 \\
\hline 3 & SB_33 & 1 & 33.0 & 0.9594 & -19.51 \\
\hline 4 & KB_33 & 1 & 33.0 & 0.9594 & -19.51 \\
\hline 5 & SD_33 & 1 & 33.0 & 0.9594 & -19.51 \\
\hline 6 & TS_33 & 1 & 33.0 & 0.9524 & -23.99 \\
\hline 7 & SM_33 & 1 & 33.0 & 0.9499 & -24.28 \\
\hline 8 & BS_33 & 1 & 33.0 & 0.9709 & -23.60 \\
\hline 9 & KG_33 & 1 & 33.0 & 0.9543 & -25.46 \\
\hline 10 & LD_33 & 1 & 33.0 & 0.9545 & -25.73 \\
\hline 11 & PI_33 & 1 & 33.0 & 0.9549 & -24.88 \\
\hline 12 & MS_33 & 1 & 33.0 & 0.9538 & -25.07 \\
\hline 13 & TR_33 & 4 & 33.0 & 1.0000 & 0.00 \\
\hline 14 & SA_33 & 1 & 33.0 & 0.9615 & -23.11 \\
\hline 15 & SR_33 & 1 & 33.0 & 0.9593 & -19.52 \\
\hline 16 & LP_33 & 1 & 33.0 & 0.9615 & -23.11 \\
\hline 17 & LK_33 & 1 & 33.0 & 0.9593 & -19.52 \\
\hline 18 & SC_33 & 1 & 33.0 & 0.9580 & -24.01 \\
\hline 19 & UB_33 & 1 & 33.0 & 0.9580 & -24.01 \\
\hline 20 & BM_33 & 1 & 33.0 & 0.9615 & -23.11 \\
\hline 21 & SI_33 & 4 & 33.0 & 1.0000 & 0.00 \\
\hline 22 & KG_11 & 4 & 11.0 & 1.0000 & 0.00 \\
\hline 23 & GN_11 & 2 & 11.0 & 0.9549 & -54.88 \\
\hline 24 & SG2_11 & 4 & 11.0 & 1.0000 & 0.00 \\
\hline 25 & SG1_11 & 4 & 11.0 & 1.0000 & 0.00 \\
\hline 26 & SD2_33 & 1 & 33.0 & 0.9594 & -19.51 \\
\hline 27 & BS_33 & 4 & 33.0 & 1.0000 & 0.00 \\
\hline 28 & BN_11 & 2 & 11.0 & 1.0490 & 10.42 \\
\hline 29 & LD1_11 & 2 & 11.0 & 0.9615 & -23.11 \\
\hline 30 & BG_33 & 4 & 33.0 & 1.0000 & 0.00 \\
\hline 31 & B8_11 & 4 & 11.0 & 1.0000 & 0.00 \\
\hline 32 & LD2_11 & 2 & 11.0 & 0.9615 & -23.11 \\
\hline 33 & LD3_11 & 2 & 11.0 & 0.9615 & -23.11 \\
\hline 34 & LD4_11 & 2 & 11.0 & 0.9615 & -23.11 \\
\hline
\end{tabular}


Table A2. Transformer branch data used in PSS/E.

\begin{tabular}{|c|c|c|c|c|c|c|}
\hline \multicolumn{5}{|c|}{ Transformer Branches } & \multirow{3}{*}{$\begin{array}{c}\text { Tap } \\
\text { Positions }\end{array}$} & \multirow{3}{*}{$\begin{array}{l}\text { Winding } \\
\text { MVA Base }\end{array}$} \\
\hline \multicolumn{2}{|c|}{ From Bus } & \multicolumn{2}{|c|}{ To Bus } & \multirow{2}{*}{ Id } & & \\
\hline No & Name & No & Name & & & \\
\hline 1 & KB_6.6 & 4 & KB_33 & 1 & 8 & 14.0 \\
\hline 2 & SB_6.6 & 3 & SB_33 & 1 & 8 & 14.0 \\
\hline 8 & BS_33 & 28 & BN_11 & 1 & 5 & 25.0 \\
\hline 11 & PI_33 & 23 & GN_11 & 1 & 13 & 20.0 \\
\hline 16 & LP_33 & 29 & LD1_11 & 1 & 5 & 20.0 \\
\hline 16 & LP_33 & 32 & LD2_11 & 1 & 5 & 20.0 \\
\hline 16 & LP_33 & 33 & LD3_11 & 1 & 5 & 20.0 \\
\hline 16 & LP_33 & 34 & LD4_11 & 1 & 5 & 20.0 \\
\hline
\end{tabular}

Table A3. Machines data used in PSS/E.

\begin{tabular}{ccccccccc}
\hline $\begin{array}{c}\text { Bus } \\
\text { No. }\end{array}$ & $\begin{array}{c}\text { Bus } \\
\text { Name }\end{array}$ & $\begin{array}{c}\text { Bus } \\
\text { Code }\end{array}$ & $\begin{array}{c}\text { PGen } \\
(\mathrm{MW})\end{array}$ & $\begin{array}{c}\mathrm{P}_{\text {Max }} \\
(\mathrm{MW})\end{array}$ & $\begin{array}{c}\mathrm{P}_{\text {Min }} \\
(\mathrm{MW})\end{array}$ & $\begin{array}{c}\text { QGen } \\
(\text { Mvar })\end{array}$ & $\begin{array}{c}\mathrm{Q}_{\text {Max }} \\
(\text { Mvar })\end{array}$ & $\begin{array}{c}\mathrm{Q}_{\text {Min }} \\
(\text { Mvar })\end{array}$ \\
\hline 1 & KB_6.6 & 2 & 10.00 & 10.0 & 0.0 & 7.31 & 7.31 & 0.50 \\
2 & SB_6.6 & 2 & 10.00 & 10.0 & 0.0 & 7.31 & 7.31 & 0.50 \\
23 & GN_11 & 2 & 14.76 & 19.0 & 10.0 & 12.39 & 12.39 & -7.35 \\
23 & GN_11 & 2 & 15.00 & 18.0 & 10.0 & 8.56 & 12.39 & -7.35 \\
24 & SG2_11 & 4 & 25.00 & 10.0 & 0.0 & -3.003 & 7.00 & -5.00 \\
25 & SG1_11 & 4 & 25.00 & 10.0 & 0.0 & 1.525 & 7.00 & -5.00 \\
28 & BN_11 & 2 & 15.00 & 20.0 & 0.0 & 17.468 & 21.24 & -5.22 \\
29 & LD1_11 & 2 & 9.00 & 15.0 & 8.0 & 6.648 & 11.40 & -8.50 \\
32 & LD2_11 & 2 & 9.50 & 15.0 & 8.0 & 6.603 & 11.40 & -8.50 \\
33 & LD3_11 & 2 & 15.00 & 15.0 & 8.0 & 10.185 & 11.40 & -8.50 \\
34 & LD4_11 & 2 & 15.00 & 15.0 & 8.0 & 7.224 & 11.40 & -8.50 \\
\hline
\end{tabular}


Table A4. Load data used in PSS/E.

\begin{tabular}{|c|c|c|c|c|}
\hline Bus No. & Bus Name & Id & $\mathrm{P}_{\text {load }}(\mathrm{MW})$ & $\mathrm{Q}_{\text {load }}(\mathrm{Mvar})$ \\
\hline 5 & SD_33 & 1 & 2.5730 & 1.2460 \\
\hline 5 & SD_33 & 2 & 2.8790 & 1.3950 \\
\hline 5 & SD_33 & 3 & 4.4600 & 2.1600 \\
\hline 5 & SD_33 & 4 & 0.2820 & 0.1360 \\
\hline 6 & TS_33 & 1 & 17.2890 & 8.3730 \\
\hline 6 & TS_33 & 2 & 13.1720 & 6.3790 \\
\hline 7 & SM_33 & 1 & 10.4150 & 5.0440 \\
\hline 7 & SM_33 & 2 & 4.4720 & 2.1660 \\
\hline 8 & BS_33 & 1 & 2.1810 & 1.0560 \\
\hline 8 & BS_33 & 2 & 5.8810 & 2.8480 \\
\hline 8 & BS_33 & 3 & 0.0000 & 0.0000 \\
\hline 10 & LD_33 & 1 & 6.8490 & 3.3170 \\
\hline 10 & LD_33 & 2 & 5.5260 & 2.6760 \\
\hline 11 & PI_33 & 1 & 4.4970 & 2.1780 \\
\hline 11 & PI_33 & 2 & 3.3820 & 1.6380 \\
\hline 12 & MS_33 & 1 & 6.9470 & 3.3650 \\
\hline 12 & MS_33 & 2 & 6.8490 & 3.3170 \\
\hline 15 & SR_33 & 1 & 4.0310 & 1.9520 \\
\hline 15 & SR_33 & 2 & 6.0410 & 2.9260 \\
\hline 17 & LK_33 & 1 & 5.4160 & 2.6230 \\
\hline 17 & LK_33 & 2 & 3.3570 & 1.6260 \\
\hline 26 & SD2_33 & 99 & -5.0000 & 0.0000 \\
\hline 27 & BS_33 & 99 & -10.0000 & 0.0000 \\
\hline 30 & BG_33 & 99 & -2.0000 & 0.0000 \\
\hline
\end{tabular}


Table A5. Branch/distribution line data used in PSS/E.

\begin{tabular}{|c|c|c|c|c|c|c|c|c|}
\hline \multicolumn{5}{|c|}{ Distribution Branches } & \multirow{3}{*}{$\begin{array}{l}\text { RATE1 } \\
\text { (MVA) }\end{array}$} & \multirow{3}{*}{$\begin{array}{c}\text { Length } \\
\text { (mile) }\end{array}$} & \multirow{3}{*}{ Line $\mathrm{R}(\mathrm{pu})$} & \multirow{3}{*}{ Line $\mathrm{X}(\mathrm{pu})$} \\
\hline \multicolumn{2}{|c|}{ From Bus } & \multicolumn{2}{|c|}{ To Bus } & \multirow{2}{*}{ Id } & & & & \\
\hline No & Name & No & Name & & & & & \\
\hline 3 & SB_33 & 26 & SD2_33 & 1 & 36.0 & 36.0 & 0.000000 & 0.000100 \\
\hline 4 & KB_33 & 26 & SD2_33 & 2 & 36.0 & 36.0 & 0.000000 & 0.000100 \\
\hline 5 & SD_33 & 14 & SA_33 & 1 & 36.0 & 9.0 & 0.017631 & 0.333357 \\
\hline 5 & SD_33 & 14 & SA_33 & 2 & 36.0 & 9.0 & 0.017631 & 0.333357 \\
\hline 5 & SD_33 & 26 & SD2_33 & 1 & 36.0 & 36.0 & 0.000000 & 0.000100 \\
\hline 6 & TS_33 & 7 & SM_33 & 1 & 35.5 & 6.7 & 0.024425 & 0.065831 \\
\hline 6 & TS_33 & 7 & SM_33 & 2 & 35.5 & 6.7 & 0.024425 & 0.065831 \\
\hline 6 & TS_33 & 8 & BS_33 & 1 & 18.0 & 5.6 & 0.010970 & 0.207422 \\
\hline 6 & TS_33 & 8 & BS_33 & 2 & 18.0 & 5.6 & 0.010970 & 0.207422 \\
\hline 6 & TS_33 & 26 & SD2_33 & 1 & 36.0 & 10.0 & 0.019590 & 0.370397 \\
\hline 6 & TS_33 & 26 & SD2_33 & 2 & 36.0 & 10.0 & 0.019590 & 0.370397 \\
\hline 8 & BS_33 & 9 & KG_33 & 1 & 32.6 & 0.7 & 0.005039 & 0.007713 \\
\hline 8 & BS_33 & 9 & KG_33 & 2 & 32.6 & 0.7 & 0.005039 & 0.007713 \\
\hline 9 & KG_33 & 10 & LD_33 & 1 & 43.7 & 6.7 & 0.020426 & 0.062755 \\
\hline 9 & KG_33 & 10 & LD_33 & 2 & 43.7 & 6.7 & 0.020426 & 0.062755 \\
\hline 9 & KG_33 & 11 & PI_33 & 1 & 18.0 & 3.5 & 0.059158 & 0.125699 \\
\hline 9 & KG_33 & 11 & PI_33 & 2 & 18.0 & 3.5 & 0.059158 & 0.125699 \\
\hline 11 & PI_33 & 12 & MS_33 & 1 & 18.0 & 1.2 & 0.020283 & 0.043097 \\
\hline 11 & PI_33 & 12 & MS_33 & 2 & 18.0 & 1.2 & 0.020283 & 0.043097 \\
\hline 11 & PI_33 & 14 & SA_33 & 1 & 35.5 & 14.0 & 0.051038 & 0.137557 \\
\hline 11 & PI_33 & 18 & SC_33 & 1 & 35.5 & 9.0 & 0.032810 & 0.088430 \\
\hline 12 & MS_33 & 27 & BS_33 & 1 & 0.0 & 36.0 & 0.000000 & 0.000100 \\
\hline 14 & SA_33 & 16 & LP_33 & 1 & 18.0 & 0.2 & 0.003380 & 0.007183 \\
\hline 14 & SA_33 & 16 & LP_33 & 2 & 18.0 & 0.2 & 0.003380 & 0.007183 \\
\hline 14 & SA_33 & 18 & SC_33 & 1 & 35.5 & 9.5 & 0.034633 & 0.093343 \\
\hline 14 & SA_33 & 20 & BM_33 & 1 & 35.5 & 9.0 & 0.032810 & 0.088430 \\
\hline 14 & SA_33 & 20 & BM_33 & 2 & 35.5 & 9.0 & 0.032810 & 0.088430 \\
\hline 15 & SR_33 & 17 & LK_33 & 1 & 36.0 & 0.0 & 0.000000 & 0.000100 \\
\hline 17 & LK_33 & 26 & SD2_33 & 1 & 35.5 & 0.1 & 0.000365 & 0.000983 \\
\hline 17 & LK_33 & 26 & SD2_33 & 2 & 35.5 & 0.1 & 0.000365 & 0.000983 \\
\hline 18 & SC_33 & 19 & UB_33 & 1 & 35.5 & 0.0 & 0.000000 & 0.000100 \\
\hline 18 & SC_33 & 19 & UB_33 & 2 & 35.5 & 0.0 & 0.000000 & 0.000100 \\
\hline
\end{tabular}

